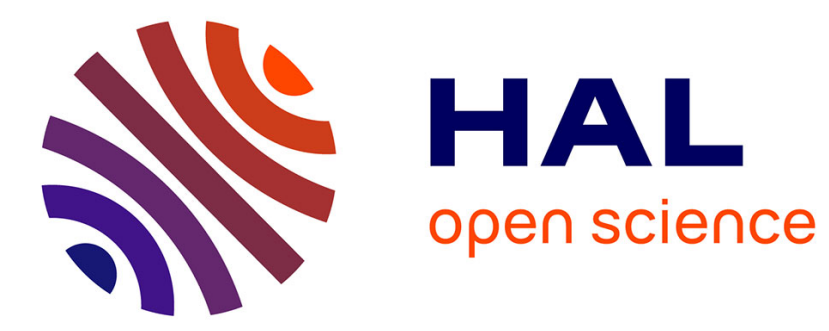

\title{
Improving rheological sludge characterization with electrical measurements
}

E. Dieudé-Fauvel, H. van Damme, J.C. Baudez

\section{To cite this version:}

E. Dieudé-Fauvel, H. van Damme, J.C. Baudez. Improving rheological sludge characterization with electrical measurements. Chemical Engineering Research and Design, 2009, 87, p. 982 - p. 986. 10.1016/j.cherd.2008.10.010 . hal-00455518

\section{HAL Id: hal-00455518 \\ https://hal.science/hal-00455518}

Submitted on 10 Feb 2010

HAL is a multi-disciplinary open access archive for the deposit and dissemination of scientific research documents, whether they are published or not. The documents may come from teaching and research institutions in France or abroad, or from public or private research centers.
L'archive ouverte pluridisciplinaire HAL, est destinée au dépôt et à la diffusion de documents scientifiques de niveau recherche, publiés ou non, émanant des établissements d'enseignement et de recherche français ou étrangers, des laboratoires publics ou privés. 
Author-produced version of the paper published in Chemical Engineering Research and Design, 2009, 87,982-986 , available at http://www.sciencec doi : 10.1016/j.cherd.2008.10.010

\title{
Improving rheological sludge characterization with electrical measurements
}

\author{
Dieudé-Fauvel E. ${ }^{1}$, Van Damme, H. ${ }^{2}$, Baudez, J.C. ${ }^{1^{*}}$ \\ ${ }^{1}$ Cemagref, Domaine des Palaquins, F-03150 Montoldre \\ ${ }^{2}$ ESPCI-PPMD, 10 rue Vauquelin, F-75231 Paris cedex 05
}

*to whom correspondence should be sent: jean-christophe.baudez@cemagref.fr

Tel. +33.(0)4.70.45.73.60 Fax. +33.(0)4.70.45.19.46

\section{Abstract}

The present work is an attempt to obtain information on the rheological behaviour of sewage sludge by performing electrical resistivity measurements. The underlying hypothesis is that, in such gel-like complex fluids, the electrical conductivity is determined not only by the free ions charge and mobility in the interstitial solution, like in simple electrolyte solutions, but also by the structure and the dynamics of the macromolecular and colloidal network. In addition, electrical measurements offer the advantage of being a non-destructive technique suitable for implementation in the field. The viscosity and resistivity of sludges containing between 4 and 15\% dry matter were measured as a function of three parameters: (i) temperature, from 278 to $323 \mathrm{~K}$, (ii) added salt concentration, between 0 and $22.3 \% \mathrm{KCl}$ with respect to dry mass and (iii) ageing, from 0 to 25 days. Both viscosity and resistivity were found to follow the same non-Arrhenius temperature dependence, typical of cooperative molecular motions in glass-forming liquids, with the same thermodynamic parameters. In spite of this complex behaviour, a linear relationship between viscosity and resistivity was obtained. This linear relationship was destroyed by the addition of salt and by ageing, but an empirical parameter combining resistivity and viscosity could still be linearly related to 
1 resistivity, allowing for the indirect determination of the sludge viscosity from electrical measurements.

4 Keywords: on-line characterization, rheology, resistivity, sludge

\section{Introduction}

Since the beginning of the seventies with the pioneering work of Colin (1970) or Campbell and Crescuollo (1982), rheological measurements proved to be of great interest to estimate quantitatively the physical consistency of sewage sludge. An accurate estimation of this consistency is required for the design of pumping systems or for the control of the dewatering steps, (Dentel, 1997). Nevertheless, rheological measurements remain hard to perform especially in-situ. As far as we know, except for the work of Abu-Orf and Dentel (1997) focusing on the conditioning part, rheological measurements are performed ex-situ, after sampling and lab treatment. Plant management is then extrapolated from the lab test. In order to bypass this operating sequence, it appears desirable to develop a fast and easy characterization method suitable for routine use in control process. Ideally, this method should also be non destructive in order to be as representative as possible of the material during the treatment process.

Another reason to look for non destructive in situ characterization methods is the continuous evolution of the sludge composition due to micro-biological activity. This evolution is

21 particularly strong in digesters, where the temperature plays an important role. Monteiro 22 (1997) and Baudez and Coussot (2001) evidenced that the rheological parameters are 23 decreasing during storage. In that case, it appears quite difficult to determine a priori the 24 rheological behaviour by using global macroscopic parameters such as the solid content 25 which remains the standard to distinguish different materials. As shown by Spinosa and 
1 Whichmann (2004), this parameter cannot be used alone to classify sludge behaviours.

2 Surface charges (Forster, 82, 83, 2002) and fat content (Baudez and Coussot, 2001) also

3 influence deeply the apparent sewage sludge consistency.

4 The present work is an attempt to obtain information on the rheological behaviour of sewage

5 sludge by performing electrical resistivity measurements. Electrical resistivity measurements

6 have been used for decades in oil exploration and in soil science as probe of the pore network

7 geometry (tortuosity) and saturation in electrolyte solution. (Fukue et al., 1999; Besson et al.,

8 2004), but no equivalent effort has been done on complex fluids. If successful, it would be a

9 non-destructive technique suitable for implementation in the field. The underlying hypothesis

10 is that, in such gel-like complex fluids, the electrical conductivity is determined not only by

11 the free ions charge and mobility in the interstitial solution, like in simple electrolyte

12 solutions, but also by the structure and the dynamics of the macromolecular and colloidal

13 network, including the non-conducting lipid phase.

14 In simple electrolytic solutions, the relationship between resistivity and viscosity is linear and straightforward. Only free ions contribute to the solution conductivity and the only source of 16 energy dissipation is through viscous friction in the solvent. Thus,

$$
\rho \approx 6 \pi \eta_{0}\left(\frac{1}{F e}\right)\left(\sum_{i} \frac{z_{i} c_{i}}{r_{i}}\right)^{-1}
$$

where $\rho$ and $\eta_{0}$ are the solution resistivity and viscosity, respectively. $z_{i}, c_{i}$ and $r_{i}$ are the ionic charge, concentration and radius, respectively, for ionic species $i . F$ and $e$ are the Faraday and unit electronic charge, respectively. Eq. 1 is basically the Stokes-Einstein equation for the viscous friction coefficient of spherical species in a uniform medium.

Eq. 1 can easily be modified in order to take into account the presence of an electrically insulating phase of volume fraction $\phi$. For instance, in the high dilution limit, using the 
1 Maxwell mixture model for conductivity and the Einstein model for the viscosity of dilute

2 suspensions, resistivity and viscosity are related to $\phi$ by the following simple relationships:

$$
\begin{aligned}
& \rho=\rho_{0} /(1-\phi) \\
& \eta=\eta_{0}(1+2.5 \phi)
\end{aligned}
$$

In that case, resistivity and viscosity are still expected to be approximately linearly related to each other.

The relationship between resistivity and viscosity is much less obvious in complex fluids where the interactions between non-solvent species, that is "dry matter" (neutral or charged macromolecules, colloidal particles, micellar assemblies, lipids...), leads to non-Newtonian behaviour and strong departure from Einstein's law, even at very low volume fraction of nonsolvent species. In spite of this, as will be shown in the following, rather simple and reliable empirical relationships between resistivity and viscosity can be obtained. We first demonstrate that there is the same temperature dependency for both the resistivity and the apparent viscosity of liquid and pasty sludge. Then we underline that a strong correlation can be defined between elasticity and conductivity evolutions for various sludge concentration and during storage. Finally, we also analyze the influence of salt addition onto the electrical and rheological behaviours.

\section{Material and methods}

\section{Sludge preparation}

Sludges were picked up in the WWTP of Moulins (50.000 equivalent inhabitants, Allier, Centre of France), after being dewatered by filter belts or within the aerated tank. The dry matter was approximately equal to $15 \%$ for the pasty material and $4 \%$ for the liquid sludge. This parameter was determined by drying the material at $60^{\circ} \mathrm{C}$ during 72 hours (ASAE Standards, 1999). 
1 According to the objectives of our experiments, the material was first homogenised just

2 after sampling with a long shear (20 minutes at $100 \mathrm{rpm}$ using a Rayneri turbotest) and 3 then prepared as follow: 22 demonstrated (Coleman et al., 1966) that $\gamma=-r \frac{\partial \varphi}{\partial r}$ (and equivalently $\dot{\gamma}=-r \frac{\partial \omega}{\partial r}$ ) and $23 \tau=\frac{M}{2 \pi h r^{2}}$, in which $M$ is the torque applied to the inner cylinder and $\gamma$ is the

- Storage: a sufficient quantity of a raw sludge was picked up in the plant and left at rest in an air tight box in order to reproduce storage anaerobic conditions.

- Salt addition: potassium chloride was added at various concentrations from 0 to $22.3 \%$ of the initial dry mass of sludge to modify the free charges concentration.

- Temperature dependence: for rheological and electrical measurement, samples were submitted to a slow ramp, from 4 to $35^{\circ} \mathrm{C}$ by using a thermostatic bath. The upper limit was chosen to limit evaporation phenomena.

Except for the storage experiment, all the samples were stored at $4{ }^{\circ} \mathrm{C}$.

\section{Rheological measurement}

Rheological measurements were done with a MCR300 rheometer (Paar Physica), equipped with a coaxial cylinders geometry with large gap and rough surfaces (inner radius $=12.5 \mathrm{~mm}$, outer radius $=19.5 \mathrm{~m}$, length $=70 \mathrm{~mm}$ ). Such geometry enables to compare a large range of sludge, from very liquid to pasty. It also minimizes evaporation losses and allows to overcome sludge heterogeneities by using large volumes.

In a Couette geometry, in the absence of inertia and edge effects, it may be 
1 deformation, $\dot{\gamma}$ the shear rate, $\varphi$ the rotation angle, $\omega$ the rotation velocity, and $\tau$ the

2 shear stress, within the material.

3 To avoid changes due to the chemical and microbiological evolution of sludge, fast

4 rheological tests were needed. The experimental protocol had to be quite short. Except

5 for the temperature dependence, experiments were done at $6^{\circ} \mathrm{C}$.

6 The apparent viscosity was determined as follow: after being presheared during 2

7 minutes at $180 \mathrm{rpm}$, the sludge is left at rest during 1 minute. Then a constant shear rate

8 equals to $100 \mathrm{~s}^{-1}$ was applied until the corresponding shear stress reach a constant

9 value. The apparent viscosity $\eta$ is the ratio between the shear stress and the shear rate.

10 For the temperature impact, the sludge was submitted during 90 minutes to a constant

11 shear rate while the temperature slowly increased.

\section{Electrical measurement}

14 Electrical impedance spectroscopy consists in applying an alternative current over a sweep of 15 frequencies and measuring the response of the system. We used an Agilent 4294A Precision 16 Impedance Analyzer, with a two electrodes probe (diameter $2.95 \mathrm{~mm}$, gap $49.6 \mathrm{~mm}$, 17 immerged length $73.75 \mathrm{~mm}$ ). Samples were transferred into a $500 \mathrm{~mL}$ beaker, designed to keep the probe fixed (fig. 1). The current was fixed to $50 \mathrm{mV}$ and impedance measurements were obtained over frequency sweeps from $40 \mathrm{~Hz}$ to $110 \mathrm{MHz}$. Each value represented an average of at least three measurements. The standard variation was less than $5 \%$.

21 The measurements gave us the phase angle and the complex impedance modulus $|Z|$, from

22 which we deduced the resistivity $\rho$, simply by knowing the tools dimensions: $|Z|=\rho \frac{L}{S}$

23 where $\mathrm{L}$ was the electrode length and $\mathrm{S}$ the beaker surface. 


\section{$1 \quad$ Results and discussion}

\section{Temperature dependence}

3 When the temperature increased, the sludge became fluider, its apparent viscosity decreased

4 (fig. 2). In the same time, its ability to let the current flow was better: the resistivity decreased

5 (fig. 3), both following a (slightly modified) Vogel-Tammann-Fulcher (VTF) model (Eq. 1$6 \quad 2):$

$7 \quad \eta=a \exp \left(\frac{b}{T-T_{0}}\right)+c$

$8 \quad \rho=\alpha \exp \left(\frac{\beta}{T-T_{0}}\right)+\delta$

9 Moreover, viscosity and resistivity had exactly the same activation energy $(b=\beta)$, suggesting

10 that the same molecular movements and interactions are probably involved in both viscous

11 flow and charges mobility. This result confirms that electrical measurements can be used to

12 complete rheological analysis.

13 The equality of activation energy also implied that there is a linear relation between those 14 properties, viscosity and resistivity, in the same way as for liquid electrolytes (fig. 4), except 15 that our relation is shifted by a constant factor:

$16 \rho=k \eta+\lambda$

17 Equation (3) reminds the relation of proportionality between resistivity and viscosity of 18 electrolytes (Gueguen and Palciauskas, 1992).

Salt addition

21 Adding free charges within the sludge induced both a decrease of the viscosity and a decrease 22 of the resistivity. However, the correlation between viscosity and resistivity is not a straight 23 line (fig. 5), like for temperature dependence. This result suggests that the parameters $k$ and $\lambda$ 
1 of equation (3) depend on sludge composition and more precisely on free charge

2 concentration.

3 Nevertheless, by changing the viscosity into the ratio between resistivity and viscosity, which

4 represents ionic species concentration in electrolytes, we get a linear relationship between the

5 resistivity and the variable $\frac{\rho}{\eta}$ (fig. 6).

6 Thus, we obtain:

$7 \quad \rho=m \cdot \frac{\rho}{\eta}+n \Leftrightarrow \rho=\frac{n \eta}{m-\eta}$

8 In the case of free charges addition, equation (4) demonstrates that it is possible to determine

9 the sludge viscosity simply by measuring its resistivity, which is a fast, easy and non

10 destructive measurement. This method can thus be made in situ and in routine.

\section{Sludge aging}

13 The previous results demonstrated that (i) the same molecular movements and interactions are 14 involved in both viscous flow and charges mobility, (ii) there is a linear relationship between

15 the viscosity and the resistivity when the initial composition (and the structure) remain 16 unchanged and (iii) there is a linear relationship between the resistivity and the ratio 17 resistivity/viscosity when free charges are added, all things being equal.

18 Consequently, it appeared quite logical to consider that both the structure and the ionic 19 species allow to let the current flow. Considering that the current flow through the structure is 20 due to surface charges and that surface charges give a picture of the solid structure and its 21 interactions, we can write:

$22 \rho=f($ free charges; surface charges $)=f\left(\frac{\rho}{\eta} ; \eta\right)$ 
1 In the case of sludge aging, during storage or anaerobic digestion, salt concentration and

2 composition evolved: the resistivity was found to be a linear relationship of a combination of

3 both the viscosity and the ratio resistivity/viscosity (fig. 7) whichever the sludge

4 concentration:

$5 \quad \rho=p \cdot\left(\xi \cdot \eta+\zeta \cdot \frac{\rho}{\eta}\right)+q$

6 With such an approach, electrical characteristics allow to short-circuit the concentration or the

7 origin of the sludge. Whichever their treatment, their concentration or their compounds,

8 sludge can be compared only by knowing their mechanical and electrical characteristics.

9 From equation (6), the viscosity can be written as a univocal relationship of the resistivity.

10 This result demonstrateed that rheological characterization can be improved by electric 11 measurements which are non-destructive: highly shear dependent parameters, such a floc 12 aggregation, can be now determined. This new approach can also easily replace CST test 13 which is nothing more than a viscosity measurement and which is not unanimously 14 recognized- to determine sludge flocculation ability.

\section{Conclusion}

17 Viscosity and resistivity both represent transport properties and can be correlated to improve sludge characterisation. When the solid composition remained unchanged, a linear 19 relationship can be found between these two quantities while during aging or fermentation, 20 ionic species, which can be seen as electrolytes, must be taken into account. Then, a linear 21 combination between viscosity and resistivity/viscosity was defined. This variable was found to follow a linear relationship with the resistivity during sludge aging.

23 Such a result offers large perspectives to improve sludge characterization by following on-line 24 and in situ treatment processes within the WWTP. 
1 Nevertheless, additional works are needed in order to determine the physical meaning of the

2 parameters highlighted in the relationships between resistivity and viscosity. This step is

3 necessary to determine these factors a priori (rather than a posteriori).

4

\section{References}

6 Abut-Orf, M., Dentel, S.K., 1997. Effect of mixing on the rheological characteristics of 7 conditioned sludge: full scale studies. Wat. Sci. Tech., 36, 11, 51-60

8 ASAE Standards, 1999. Norm S358.2 of the American society of agricultural engineers, St9 Joseph, Michigan.

Baudez, J.C, Coussot, P., 2001. Rheology of aging, concentrated, polymeric suspensions Application to pasty sewage sludges. J. Rheol. 45, 5, 1123-1139.

Besson A., Cousin I., Samouëlian A., Boizard H. and Richard G., 2004. Structural heterogeneity of the soil tilled layer as characterized by 2D electrical resistivity surveying. Soil and Tillage Research, 79, 239-249.

Campbell, H.W., Crescuollo, P.J., 1982. The use of rheology for sludge characterization. Wat. Sci. Tech., 14, 475-489.

17 Coleman, B.D., H. Markowitz and W. Noll, 1966. Viscometric flows of Non-Newtonian 18 Fluids, Springer-Verlag, Berlin, 1966.

Colin, F., 1970. Application de techniques rhéologiques à l'étude des boues résiduaires.

Centre Belge d'Etude et de Documentation des Eaux, 317, 178-187.

21 Dentel, S. K., 1997. Evaluation and role of rheological properties in sludge management. Wat. 22 Sci. Technol., 36, 11, 1-8.

23 Forster, C.F., 1982. Sludge surfaces and their relation to the rheology of sewage sludge 24 suspensions. J. Chem. Tech. Biol., 32, 799-807. 
1 Forster, C.F., 1983. Bound water in sewage sludge and its relationship to sludge surfaces and

2 sludge viscosities. J. Chem. Tech. Biol., 33B, 76-84.

3 Forster, C.F., 2002. The rheological and physico-chemical characteristics of sewage sludge".

4 Enzyme and Microb. Tech., 30, 3, 340-345.

5 Fukue M., Minato T., Horibe H. and Taya N., 1999. The micro-structures of clay given by

6 resistivity measurements. Engineering geology, 54, 43-53.

7 Gueguen, Y., Palciauskas, V., 1992. Introduction to rock physics (in French), Paris, Hermann 8 eds.

9 Monteiro, P.S., 1997. The influence of the anaerobic digestion process on the sewage sludges 10 rheological behaviour. Wat. Sci. Tech., 36 (11), 61-67.

11 Spinosa, L., Wichmann, K., 2004. Sludge characterisation: the role of physical consistency. 12 Wat. Sci. Technol., 49, 10, 59-65.

13

\section{Acknowledgements}

15 The authors are grateful to ADEME (French energy and environment agency) for its financial 16 support. 


\section{Captions}
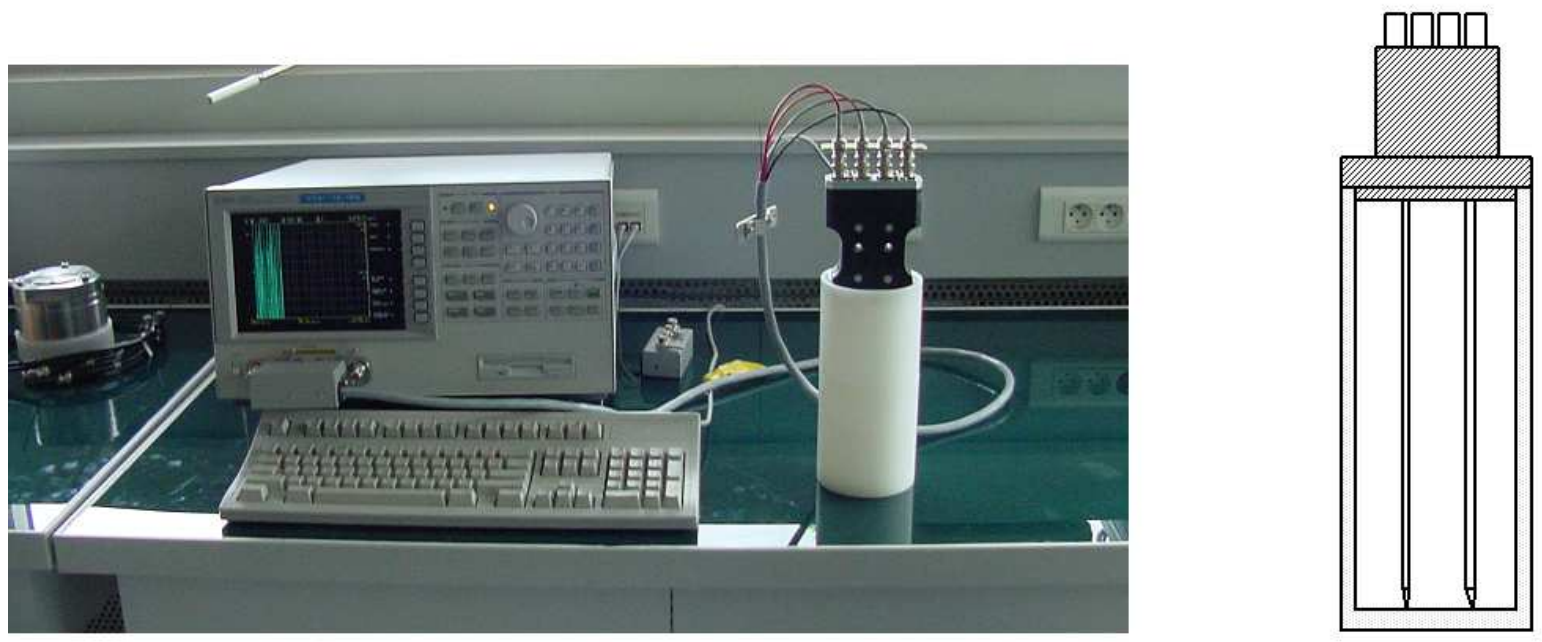

2

3

4

5

Figure 1: scheme of the electrical measurement system with the probes.

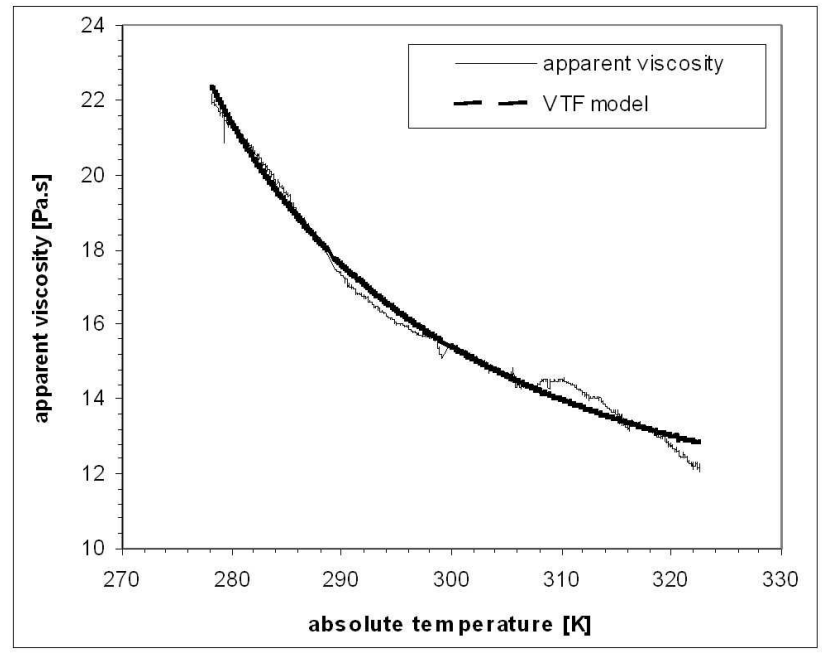

Figure 2: evolution of the apparent viscosity in relationship with the temperature for a pasty sludge at $15 \%$ of dry matter. The dotted line represents the model of equation (1) with the following parameters: $a=0.95 ; b=90.6 ; T_{0}=244 ; c=10.5 ; R^{2}=0.98$ 


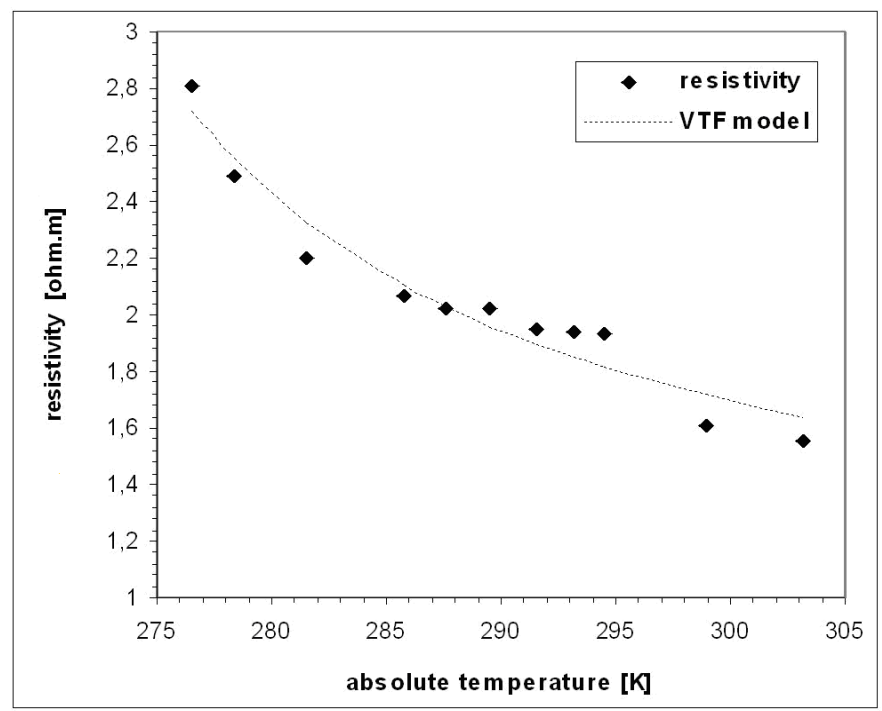

2 Figure 3: evolution of the resistivity in relationship with the temperature for a pasty sludge at $15 \%$ of dry matter. The dotted line represents the model of equation (2) with the following parameters: $\alpha=3.17$;

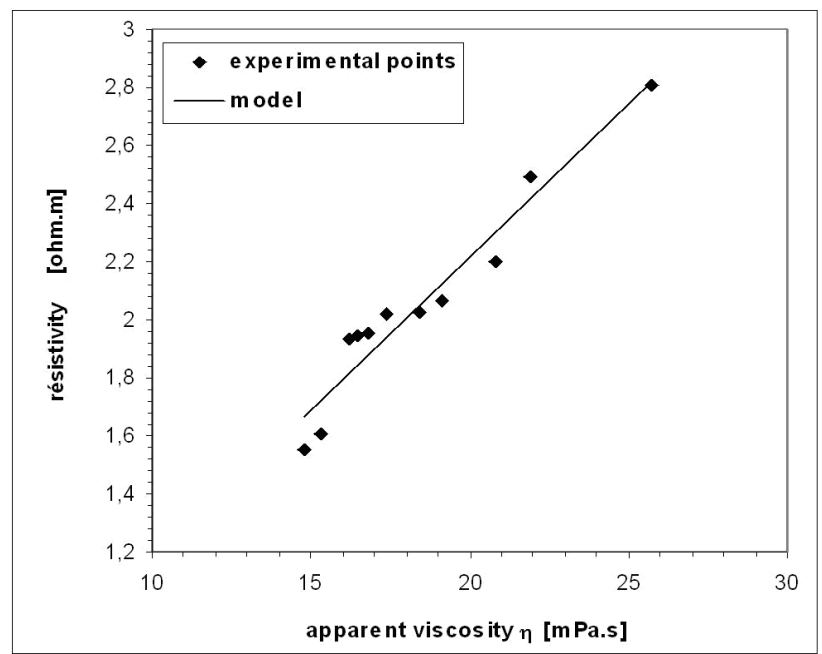

Figure 4: relation between the resistivity and the viscosity for a pasty sludge at $15 \%$ of dry matter. The straight line represents the model of equation (3) with the following parameters: $k=0.106 ; \lambda=0.101$; 


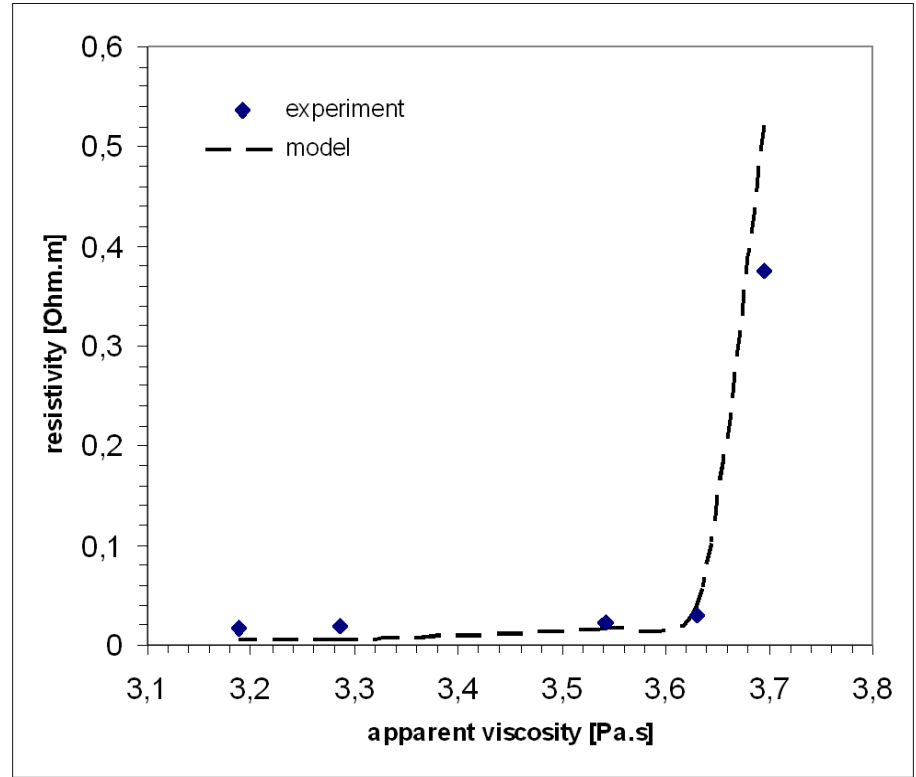

2 Figure 5: evolution of the resistivity in relationship with the apparent viscosity for a pasty sludge for with

3 the concentration of free charge was modifed. The dotted line represents the model of equation (4) with

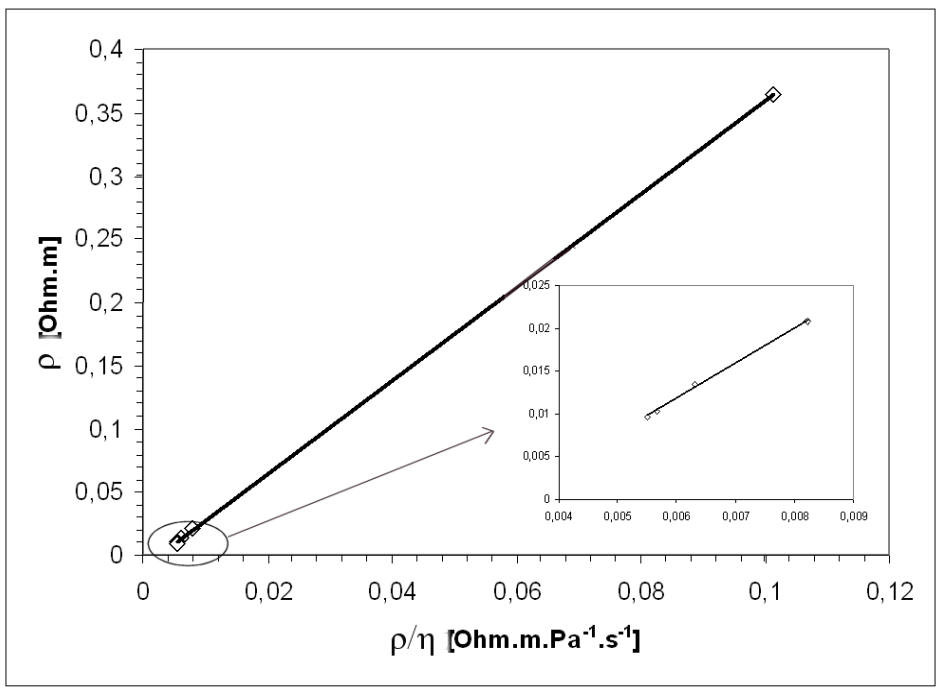

8 Figure 6: relation between the resistivity and the ratio resistivity divided by viscosity for a pasty sludge at various salt concentrations. 


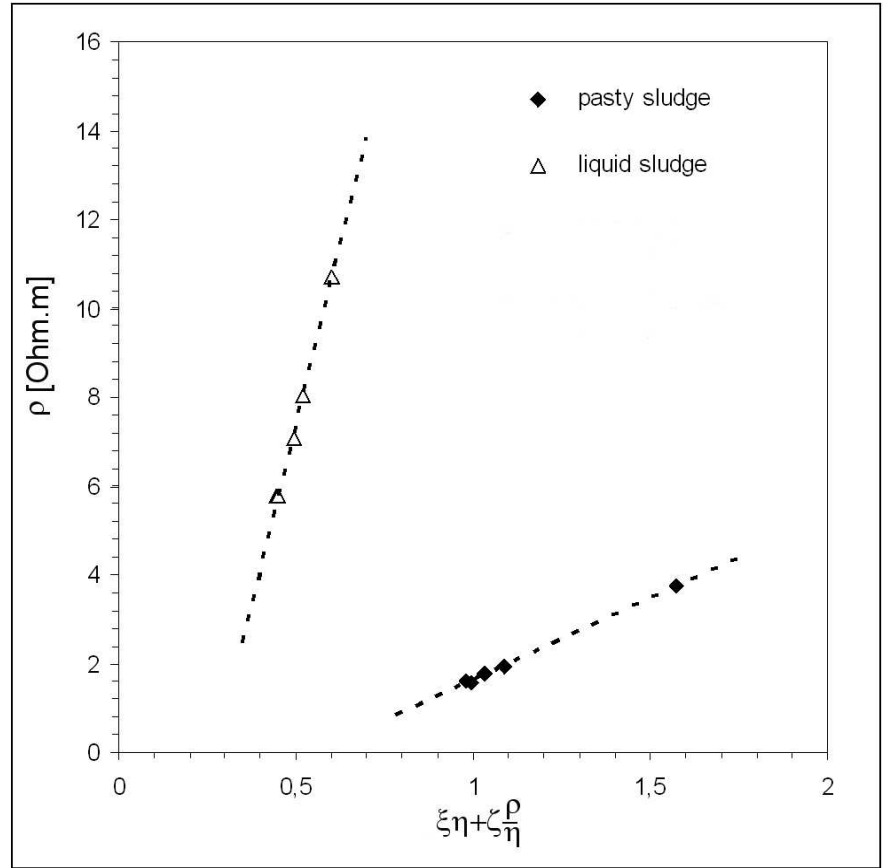

2 Figure 7: evolution of the resistivity in relationship with a linear function of the viscosity and the ratio 3 resistivity/viscosity. The dotted lines represent the model of equation (6) for a liquid and a pasty sludge.

4 The parameters of the model are: $\xi=0.1 ; \zeta=1.5 ; p=3,7 ; q=-2.05 ; R^{2}=0.99$ (pasty) and $\xi=7 ; \zeta=1.2 \mathrm{E}-03$; $\mathrm{p}=32.1 ; \mathrm{q}=-8.7 ; \mathrm{R}^{2}=0.99$

6 